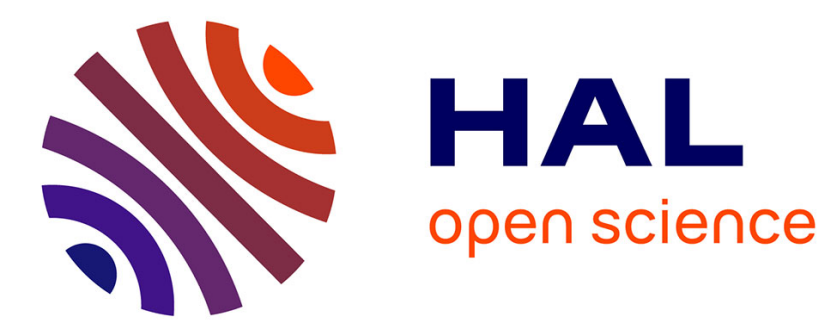

\title{
Satellite-Based Reconstruction of the Tropical Oceanic Clear-Sky Outgoing Longwave Radiation and Comparison with Climate Models
}

Guillaume Gastineau, Brian J. Soden, Darren L. Jackson, Chris W. O'dell

\section{- To cite this version:}

Guillaume Gastineau, Brian J. Soden, Darren L. Jackson, Chris W. O'dell. Satellite-Based Reconstruction of the Tropical Oceanic Clear-Sky Outgoing Longwave Radiation and Comparison with Climate Models. Journal of Climate, 2014, 27 (2), pp.941-957. 10.1175/JCLI-D-13-00047.1 . hal-01140012

\section{HAL Id: hal-01140012 \\ https://hal.science/hal-01140012}

Submitted on 16 Jun 2016

HAL is a multi-disciplinary open access archive for the deposit and dissemination of scientific research documents, whether they are published or not. The documents may come from teaching and research institutions in France or abroad, or from public or private research centers.
L'archive ouverte pluridisciplinaire HAL, est destinée au dépôt et à la diffusion de documents scientifiques de niveau recherche, publiés ou non, émanant des établissements d'enseignement et de recherche français ou étrangers, des laboratoires publics ou privés. 


\title{
Satellite-Based Reconstruction of the Tropical Oceanic Clear-Sky Outgoing Longwave Radiation and Comparison with Climate Models
}

\author{
Guillaume Gastineau \\ LOCEAN/IPSL, Université Pierre et Marie Curie, Paris, France \\ BRIAN J. SODEN \\ Rosenstiel School of Marine and Atmospheric Sciences, University of Miami, Miami, Florida \\ DARREN L. JACKSON \\ CIRES, University of Colorado at Boulder, Boulder, Colorado \\ CHRIS W. O'DELL \\ Department of Atmospheric Science, Colorado State University, Fort Collins, Colorado
}

(Manuscript received 22 January 2013, in final form 16 September 2013)

\begin{abstract}
The changes of the outgoing longwave radiation (OLR) in clear-sky conditions have been calculated using High Resolution Infrared Radiation Sounder (HIRS) observations from 1979 to 2004. After applying corrections for satellite orbital drift and intercalibration of the HIRS/2 data from the NOAA satellites, the OLR is calculated from a multivariate regression over the tropical ocean region. The clear-sky OLR retrievals compare well with the observed top-of-atmosphere radiation measurements, although the precision and stability uncertainties are larger. While the tropical ocean surface temperature has risen by roughly $0.2 \mathrm{~K}$ from 1982 to 2004, the reconstructed OLR remains stable over the ocean. Consequently, there is an increase in the clear-sky greenhouse effect (GHE) of $0.80 \mathrm{~W} \mathrm{~m}^{-2} \mathrm{decade}^{-1}$. This trend is shown to be larger than the uncertainty in the stability of the HIRS retrievals.

The observations are compared with two phase 3 of the Coupled Model Intercomparison Project model ensembles: one ensemble includes both natural and anthropogenic forcings [the twentieth-century (20C) ensemble] and the other ensemble only contains natural climate variability (the control ensemble). The OLR trend in the $20 \mathrm{C}$ simulations tends to be more negative than observed, although a majority is found to be within the observational uncertainty. Conversely, the response of the clear-sky OLR to SST is shown to be very similar in observations and models. Therefore, the trend differences between the 20C simulations and observations are likely because of internal climate variability or uncertainties in the external forcings. The observed increase in GHE is shown to be inconsistent with the control ensemble, indicating that anthropogenic forcings are required to reproduce the observed changes in GHE.
\end{abstract}

\section{Introduction}

The greenhouse effect results from absorption and emission of infrared radiation by atmospheric gases. Anthropogenic activities, such as the burning of fossil fuels, strengthen the greenhouse effect both through the

Corresponding author address: Guillaume Gastineau, LOCEAN/ IPSL, Université Pierre et Marie Curie, 4 Place Jussieu, 75005 Paris, France.

E-mail: guillaume.gastineau@upmc.fr direct addition of greenhouse gases such as carbon dioxide $\left(\mathrm{CO}_{2}\right)$ and methane (Forster et al. 2007) and through indirect effects, such as the positive water vapor feedback (Ramanathan 1981), induced by the resultant warming. Clouds are also important absorbers of infrared radiation; however, their changes are less predictable and are more difficult to observe and simulate (Bony el al. 2006).

While measurements of the atmospheric composition have clearly established increases in radiatively active gases, there are few long-term measurements of

DOI: 10.1175/JCLI-D-13-00047.1 
the top-of-atmosphere (TOA) radiation necessary to deduce the atmosphere's greenhouse effect (GHE). This reflects, in large part, the lack of observations with suitable longevity and stability to monitor long-term changes in TOA radiation. The Clouds and the Earth's Radiant Energy System (CERES) (Wielicki et al. 1996) and Earth Radiation Budget Experiment (ERBE) (Barkstrom 1984) sensors offer state-of-the-art measurements of the clear-sky TOA radiative fluxes. However, the relatively short $(<15 \mathrm{yr})$ observational duration of these instruments limits their utility for climate attribution studies. This problem has been partly addressed with radiative transfer calculations using reanalysis water vapor and temperature profiles (Slingo et al. 1998). However, such estimates rely heavily on reanalysis models and are not purely independent of the climate models used for climate projections.

Observations of the TOA radiative fluxes are of great interest to assess the climate feedbacks of global climate models. In particular, the clear-sky measurements of TOA fluxes are useful to estimate the water vapor and temperature feedbacks, which are the largest climate feedback in terms of amplitude. In this study, we show that the High Resolution Infrared Radiation Sounder (HIRS) measurements from 1979 to 2004 can provide estimates of the clear-sky outgoing longwave radiation (OLR). These observations are compared to climate model simulations to assess the clear-sky OLR changes simulated the models. Clouds are also crucial in understanding climate feedback. Since the presence of clouds greatly complicates the process of estimating and understanding the local strength of the greenhouse effect, this study will only be focused on clear-sky OLR changes.

In section 2, we present the model and observational data used. We briefly illustrate the corrections applied to remove orbital drift and intercalibrate the satellite records from the original HIRS dataset. In section 3, a multivariate regression is presented to deduce the OLR from the HIRS clear-sky measurements. The uncertainties and stability of the HIRS OLR are assessed, and this description is completed by a comparison with ERBE and CERES measurements. Finally, the observed changes are compared to that simulated from climate model control and historical simulations in section 4. Conclusions and discussion are given in the last section.

\section{Data and methods}

\section{a. Clear-sky HIRS/2 dataset}

\section{1) HIRS CLEAR-SKY DATA}

HIRS is an instrument that has flown onboard NOAA operational polar-orbiting satellites since 1978 (Kidwell
1998). The HIRS/2 instrument measures incident radiation primarily in the infrared region of the spectrum but includes both longwave and shortwave regions. The HIRS data were processed following the procedures described with details in Jackson and Soden (2007). The HIRS level 1B data were converted from raw counts to brightness temperature using the international Television and Infrared Observation Satellite (TIROS) Operational Vertical Sounder (TOVS) processing package (Smith et al. 1985). The data period used in this study is July 1979-December 2004. We excluded the data measured from NOAA-8 and TIROS-N because the data records were either too short in time or showed large regional gaps of missing data.

The cloudy pixels were removed with the cloud screening illustrated in Jackson and Bates (2000), which considers both spatial and temporal variations in the $11.1-\mu \mathrm{m}$ window channel brightness temperatures and applies thresholds to these variations to detect clouds. Wylie et al. (2005) indicated a $2 \%$ error in the cloud detection method, as some cloudy pixels are detected as clear. Cloud contamination is expected to occur primarily in low cloud regions where the lower-tropospheric temperature contrast between clear-sky and cloudy pixels is very low. The cloud clearing methodology remains consistent over time for all satellite instruments.

This study uses monthly-mean near-nadir brightness temperatures gridded to a $2.5^{\circ}$ resolution. The ascending and descending orbits were processed separately to better isolate drifts in the equatorial crossing time and its correction. The HIRS uncertainties due to instrument noise were reported to range from 0.1 to $0.5 \mathrm{~K}$ depending on the channels (Kidwell 1998). The aggregation onto the $2.5^{\circ}$ grid and the monthly averaging reduce this uncertainty. The cloudiness found by HIRS is more persistent over midlatitudes (Wylie et al. 2005), where low and middle clouds are frequently detected using the $11.1-\mu \mathrm{m}$ window channel, so that clear-sky near-nadir observations are more sparse over the Southern Ocean, North Atlantic, and North Pacific. Therefore, we only consider the tropical regions between $30^{\circ} \mathrm{N}$ and $30^{\circ} \mathrm{S}$ in this study.

In the following section, we illustrate the orbital drift correction and the intersatellite calibration applied to the data prior analysis.

\section{2) ORBIT DRIFT AND INTERSATELLITE CORRECTIONS}

A method was developed to produce a set of HIRS/2 brightness temperatures that mitigates the effects of changing diurnal sampling from orbital drift and intercalibration differences between satellites. Diurnal sampling bias manifests itself in two principal ways. Observations from a single satellite can drift through 

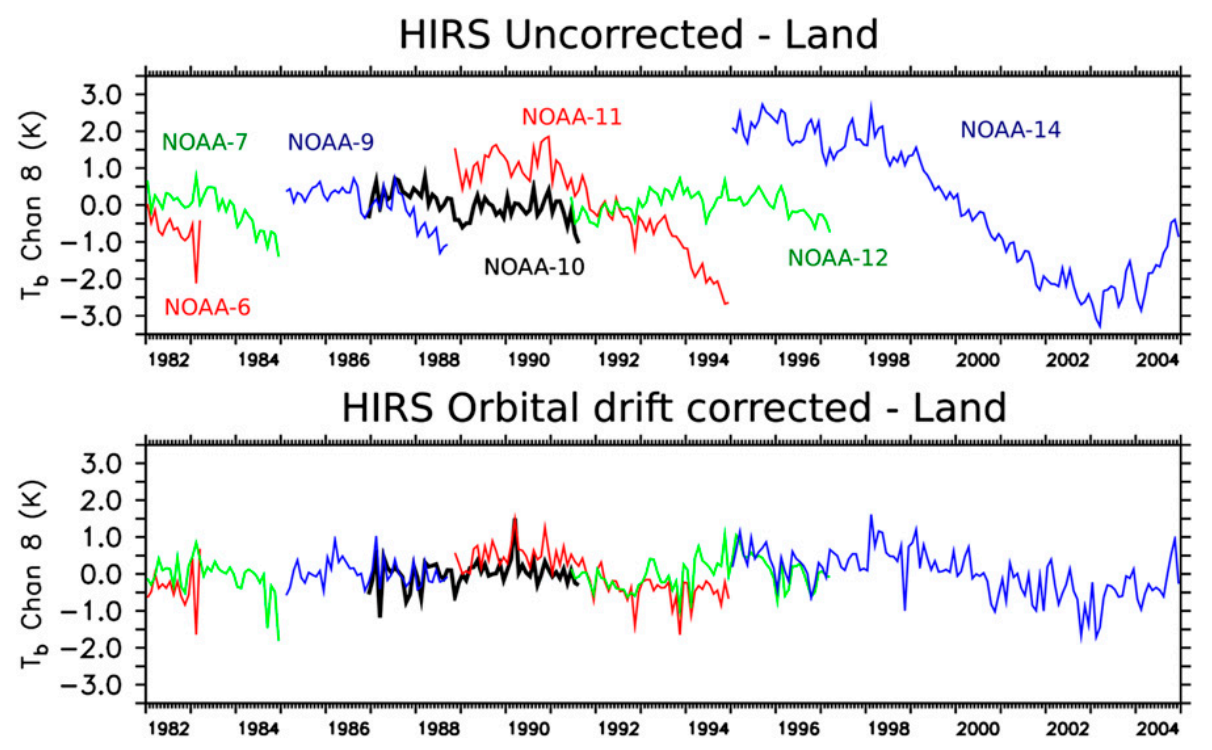

FIG. 1. Clear-sky HIRS brightness temperature $T_{b}$ observations (K) since 1979, deseasonalized anomalies, averaged between $30^{\circ} \mathrm{N}$ and $30^{\circ} \mathrm{S}$ over land, for the $11.1-\mu \mathrm{m}$ window channel (channel 8), (top) using the raw data and (bottom) after orbital drift correction of Jackson and Soden (2007).

local time as the satellite ages, thus slowly changing the observation time. Corrections to such a bias were discussed in Jackson and Soden (2007) and applied in this study. Even after the application of the drift correction, diurnal differences exist between satellites since ascending and descending node observation times differ between the various NOAA polar-orbiting satellites. Intercalibration differences occur mainly due to differences in spectral response functions between instruments (Cao et al. 2005). These biases make interpretation of observations from multiple sensors and satellite platforms challenging for climate-related research.

The first step in intersatellite bias correction was to identify and correct for diurnally sampling drift using the method of Jackson and Soden (2007). This method utilized the Geophysical Fluid Dynamics Laboratory climate model diurnal cycle to establish the diurnal trends owing to orbital drift. Application of this correction to the monthly mean brightness temperature fields only removes the time series trends caused by drifting orbits but does not correct for differences in overpass times between the satellites.

We briefly illustrate this correction for the window channel $8(11.1 \mu \mathrm{m})$, which has a strong surface contribution of around $60 \%$ and therefore shows a large influence of the orbital drift. Figures 1 and 2 illustrate the mean orbital drift correction over land and ocean respectively. The uncorrected data show a large brightness temperature decrease from 1998 to 2003 in NOAA-14 observations, as seen in the top panel of Fig. 1. A similar decrease is also apparent in the other satellites whose ascending crossing time occurs in the afternoon (NOAA-7, $N O A A-9$, and $N O A A-11)$, as they experienced a larger orbital drift. The top panel of Fig. 2 shows that the orbital drift has a much weaker influence over oceans. Note that the climatic influence of the Mt. Pinatubo eruption (June 1991) and the large 1997/98 El Niño are also apparent in the ocean data. The corrected data shows less drift over land (Fig. 1, bottom). However, there remains a small amount of drift in the NOAA-11 and NOAA-14 observations. The corrected data over land also show significant month-to-month variability that does not appear in the original dataset. In contrast, the correction is smaller for the ocean data (Fig. 2, bottom). Therefore, the data used for this study is limited to ocean data where the orbital drift correction is small. The remaining bias between satellite brightness temperatures after this correction includes intercalibration differences between satellites but also satellite differences in the observation time, now fixed in time rather than drifting in the original observations.

The second step removes the remaining intersatellite differences that include the intercalibration biases and the mean brightness temperature differences due to differences in observation time between satellites. $N O A A-10$ brightness temperatures, with local observation times of 0730 (descending orbits) and 1930 LST (ascending orbits), are used as the baseline to correct all other satellite observations. The relative adjustment of the other satellites begins by considering all overlapping monthly mean clear-sky observations between satellites, when the overlapping period exceeds 1 yr (see Fig. 3). Intersatellite 


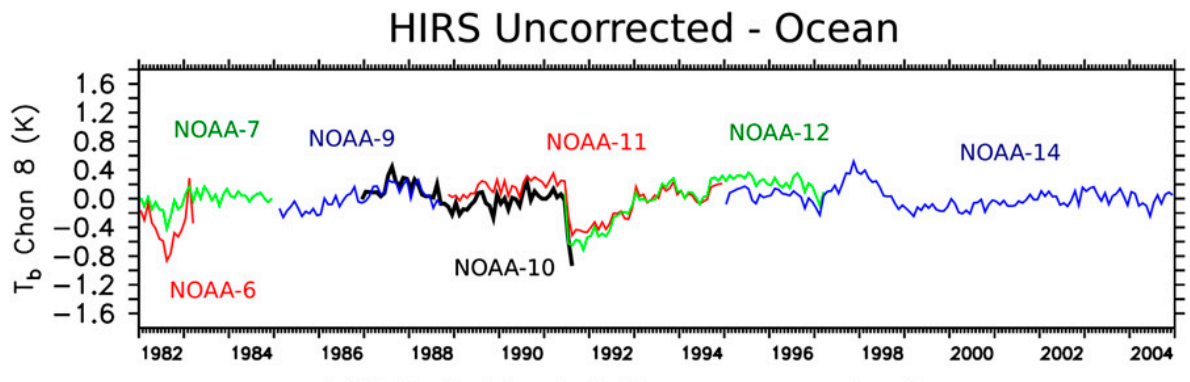

HIRS Orbital drift corrected - Ocean

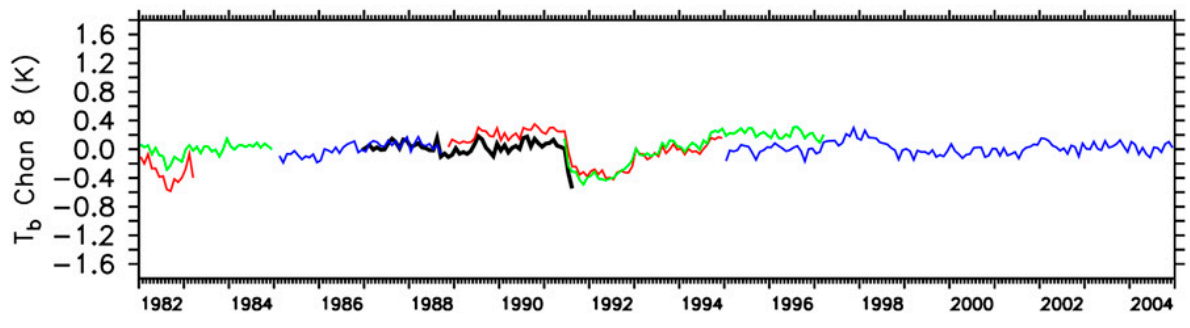

FIG. 2. As in Fig. 1, but over the ocean.

bias correction is defined as a difference between brightness temperature as a function of longitude, latitude, channel, node, and month. Unfortunately, a 1-yr overlap period does not occur between NOAA-7 and NOAA-9 observations, so HIRS observations for $N O A A-7$ were adjusted to the $N O A A-6$ morning satellite and in step these three satellites were adjusted to NOAA-10. Adjustments began with satellites coincident with the two base satellites (NOAA-10 and NOAA-6). Satellites not coincident with these satellites were corrected using adjusted satellite data derived from these two base satellites. The 12-month overlap was needed since the brightness temperatures observations taken at different times in the diurnal cycle experience vastly different amplitudes in the seasonal cycle.

The third step removes the remaining bias between the observations adjusted to NOAA-6 and satellite observations adjusted to $N O A A-10$. While less than a $30-\mathrm{min}$ diurnal time difference remains between these observations, intersatellite biases from instrument bias was evident between the time series. Adjustment to the NOAA-10 time series involved computing the mean brightness temperature difference between observations in 1984 adjusted to the NOAA-6 data with observations in 1985 adjusted to the NOAA-10 data. Mean brightness temperature differences were computed as a function of longitude, latitude, channel, and node. The intercalibrated ascending and descending monthly observations were averaged, when both are present.

The satellite observation period and the mean intersatellite calibration adjustments are given in Table 1 for channels $4,7,8$, and 12 that are used to reconstruct the OLR (see section 3). Figure 4 illustrates the intersatellite calibration results for channel $4(14.2 \mu \mathrm{m})$ brightness temperatures over the tropical oceans.

\section{b. Model data}

The observational data were compared with climate model simulations. The monthly clear-sky OLR, SST, and temperature and water vapor outputs were retrieved

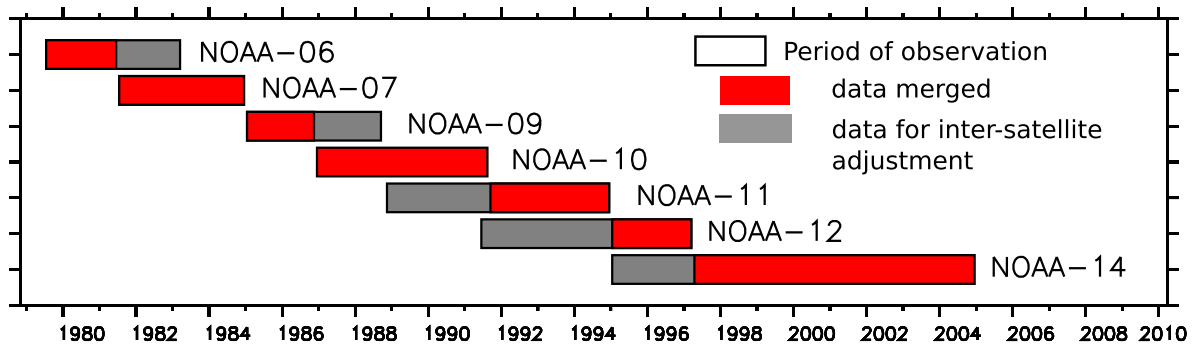

FIG. 3. Satellite observation periods of the NOAA satellites: the red rectangles indicate the data used to merge satellite observations, and the gray rectangles indicate data used to calculate the intersatellite adjustments during overlapping observing periods. 
TABLE 1. Intercalibration of HIRS clear-sky data. The mean adjustments (K) are given over ocean only, averaged between $30^{\circ} \mathrm{N}$ and $30^{\circ} \mathrm{S}$.

\begin{tabular}{llcccc}
\hline \hline & & \multicolumn{4}{c}{ Channel } \\
\cline { 3 - 6 } Satellite & \multicolumn{1}{c}{ Period } & 4 & 7 & 8 & 12 \\
\hline NOAA-06 & Jul 1979-Jun 1981 & -0.4 & +0.0 & +0.8 & -0.0 \\
NOAA-07 & Jul 1981-Dec 1984 & +0.2 & -1.0 & -0.1 & +0.1 \\
NOAA-09 & Jan 1985-Nov 1986 & +2.1 & +0.2 & -0.1 & -0.5 \\
NOAA-10 & Dec 1986-Aug 1991 & & & & \\
NOAA-11 & Sep 1991-Dec 1994 & +0.1 & -0.2 & -0.3 & +0.5 \\
NOAA-12 & Jan 1995-Mar 1997 & +1.2 & -0.1 & -0.3 & -0.5 \\
NOAA-14 & Apr 1997-Dec 2004 & -0.4 & -0.8 & -0.4 & +0.4 \\
\hline
\end{tabular}

from the multimodel dataset of phase 3 of the World Climate Research Program Coupled Model Intercomparison Project (CMIP3). The outputs of the preindustrial control (CTRL), twentieth-century (20C) (1975-2000), and A1B (2000-04) simulations were studied for 21 models (see Table 2). Among those models, 11 account for volcanic aerosols in the 20C simulations. For HadGEM1, both simulations with and without volcanic aerosols were included in this study. Several ensemble members were used for most models. Table 2 provides details on the resolution, the number of ensemble members per model, and the total length of the CTRL simulation for all models. The multimodel mean was calculated as the mean of the ensemble means of the 21 models analyzed.
The 20C simulations include the effects of both natural and anthropogenic radiative forcings, while A1B simulations include only anthropogenic forcings. The mean ozone and aerosol concentrations differ strongly between the 20C and A1B simulations; therefore, deseasonalized anomalies are computed separately in the two simulations. Under the hypothesis of a linear increase of the clear-sky OLR and GHE equal to that of the 20C simulation, we remove a small mean anomaly using the difference between the last six months of the $20 \mathrm{C}$ simulation and the first six months of the A1B simulation. The time series of $20 \mathrm{C}$ and $\mathrm{A} 1 \mathrm{~B}$ are then merged for each model. The merged 20C/A1B simulations are then averaged according to whether the $20 \mathrm{C}$ portion of the simulation included radiative forcing from volcanic aerosols.

Furthermore, we investigated outputs from a threemember atmosphere-only ensemble simulation of the Geophysical Fluid Dynamics Laboratory (GFDL) High Resolution Atmospheric Model (HiRAM; C180 version) that uses a high horizontal resolution of $\sim 50 \mathrm{~km}$ and 32 vertical levels. The simulations follow the Atmospheric Model Intercomparison Project (AMIP) protocol, with observed SST, sea ice distribution, and concentrations of greenhouse gases and aerosols as boundary conditions (Zhao et al. 2009). The outputs were downloaded from the multimodel CMIP5 dataset.

To allow a direct comparison between model and observations, we performed offline radiative transfer simulations following the model-to-satellite approach. The
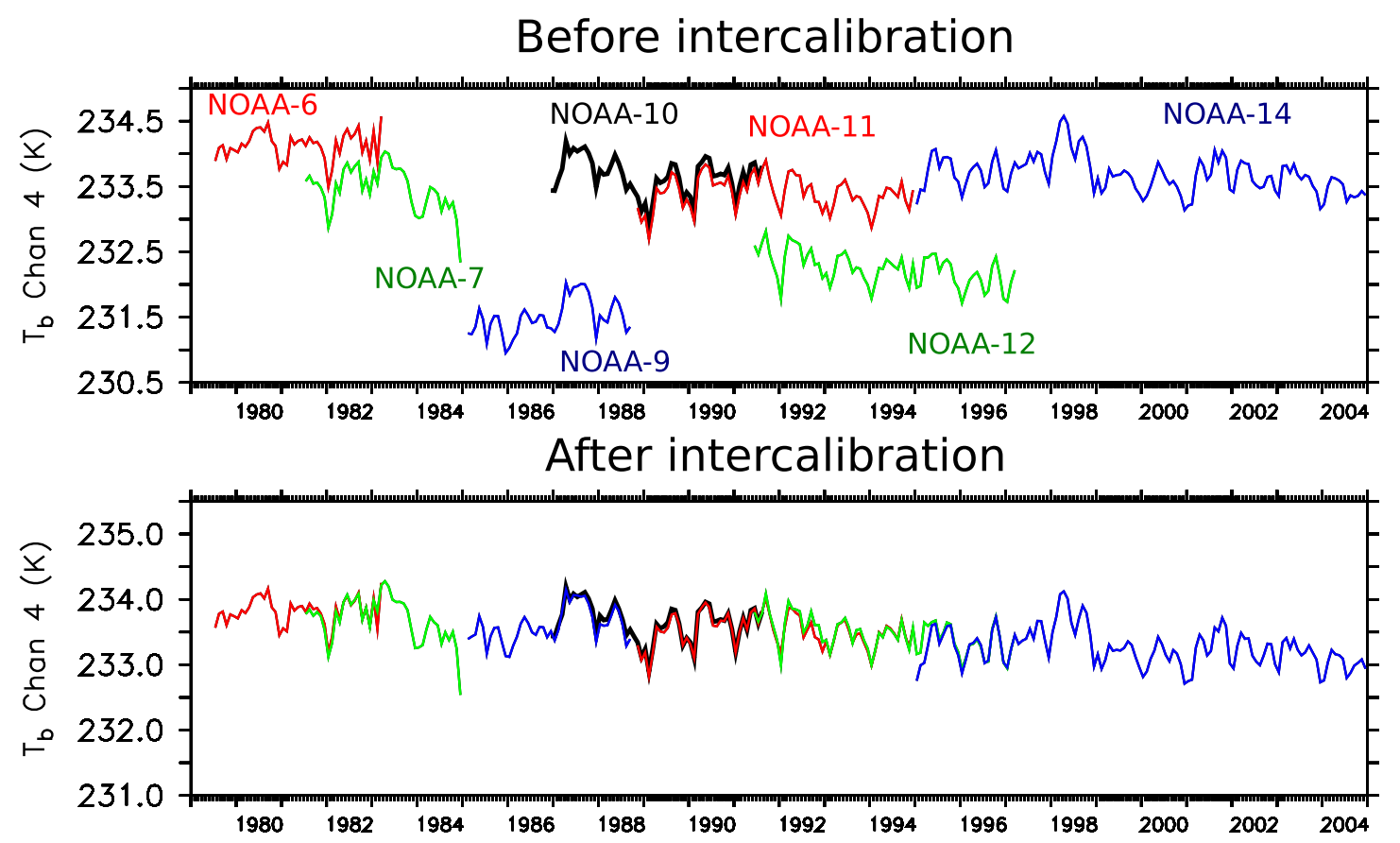

FIG. 4. Clear-sky HIRS brightness temperature $T_{b}(\mathrm{~K})$ since 1979 , averaged between $30^{\circ} \mathrm{N}$ and $30^{\circ} \mathrm{S}$ over the ocean, for the 14.2- $\mu \mathrm{m}$ channel (channel 4), (top) before and (bottom) after intercalibration. 


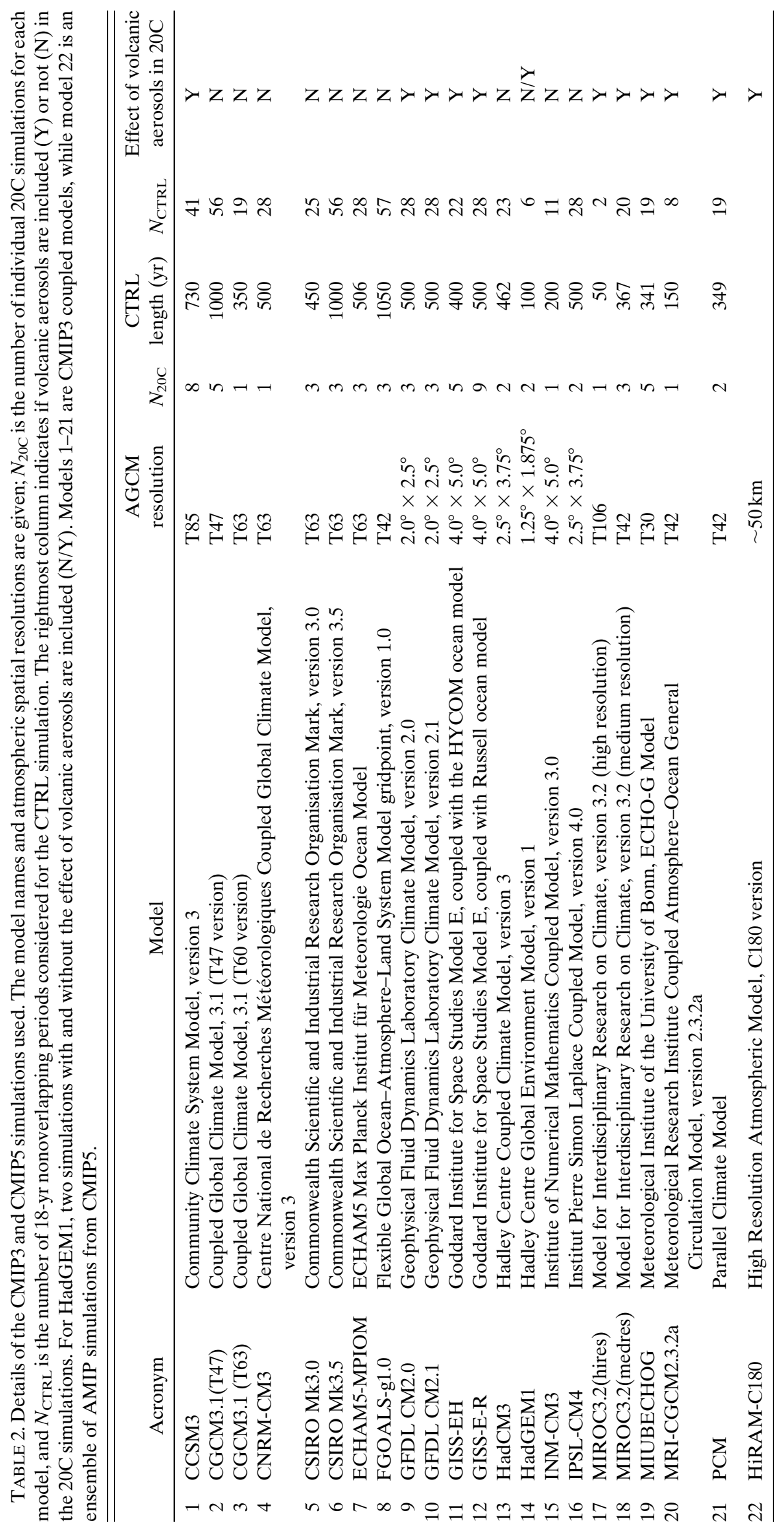


monthly HIRS brightness temperatures were simulated offline using the Radiative Transfer for TOVs, version 10.2 (RTTOV10.2) model with $\mathrm{CO}_{2}$ varying coefficients (Saunders et al. 1999) and model outputs. The HIRS brightness temperatures are simulated for all $20 \mathrm{C}$ simulations (except for MIUBECHOG, where outputs were insufficient) and for the atmosphere-only HiRAM simulations.

\section{c. Other data}

The clear-sky OLR from HIRS was compared to the state-of-the-art clear-sky OLR observations. We used the monthly clear-sky OLR from ERBE S-4 product (ERBE_S4_NAT), which combined both scanner and nonscanner broadband radiation data from the Earth Radiation Budget Satellite (ERBS), NOAA-9, and NOAA-10 observations between 1984 and 1990 (Barkstrom 1984). We also used the CERES product (SSF1deg-lite Ed2.5) from Terra and Aqua satellites since 2000 and 2002, respectively (Wielicki et al. 1996). These datasets were downloaded from the National Aeronautics and Space Administration Langley Atmospheric Science Data Center (http://eosweb.larc.nasa.gov).

The calculation of the GHE and OLR were made using SST and $\mathrm{CO}_{2}$ concentration datasets from 1982 to 2004. The SST is the NOAA optimum interpolation SST product (OI-SST) derived from satellite observations and buoy measurements (Reynolds et al. 2002). The atmospheric $\mathrm{CO}_{2}$ concentration is the one used in CMIP5 historical climate model simulations (Meinshausen et al. 2011).

All data were gridded to a common $2.5^{\circ}$ grid prior to analysis to allow for direct comparison with HIRS gridded observations. The time period investigated in this study is 1982-2004. The period starts at 1982 rather than 1979 because the OI-SST product begins in 1982.

\section{d. Trend, correlation, and regression analysis}

We calculated trend, correlation, and regression analyses in order to study the long-term changes of the OLR and GHE and to deduce the response to the mean tropical SST. First, we calculated the deseasonalized monthly anomalies over the tropical oceans $\left(30^{\circ} \mathrm{N}-\right.$ $30^{\circ} \mathrm{S}$ ). The aerosol influence on OLR after the Mt. Pinatubo eruption was less than $0.6 \mathrm{~W} \mathrm{~m}^{-2}$ after $2.5 \mathrm{yr}$ (Douglass and Knox 2005). To remove the influence of the El Chichón (April 1982) and Mt. Pinatubo (June 1991) eruptions, we excluded the $2.5 \mathrm{yr}$ following the Mt. Pinatubo and El Chichón eruptions before calculating trends, correlations, or regressions. After removing these two periods, the volcanic eruptions were expected to have a negligible effect on the OLR trend $\left(<0.05 \mathrm{~W} \mathrm{~m}^{-2} \mathrm{decade}^{-1}\right)$ during the overall 1982-2004 period.
The trends were estimated using least squares estimation. The level of statistical significance for trends and correlations was estimated using a modified degrees-offreedom approach accounting for the monthly autocorrelation in the time series (Bretherton et al. 1999). The trends and correlations with a level of statistical significance below $5 \%$ are shown in bold in the following sections. A smaller significance level indicates stronger evidence against the null hypothesis (there is no trend or correlation).

\section{OLR retrievals using HIRS}

\section{a. Multivariate regression of clear-sky OLR}

A multilinear regression between the HIRS brightness temperatures and OLR is developed to reconstruct the OLR form HIRS in clear-sky conditions. We perform radiative transfer simulations from a representative group of atmospheric soundings. The 2311 TIGR-2000 atmospheric profiles in clear-sky conditions (Chevallier et al. 2000) were used to simulate the HIRS brightness temperatures using the radiative transfer model RTTOV10.2 (Saunders et al. 1999), while the OLR is calculated using RRTM (Iacono et al. 2000). All simulations assume a constant emissivity of 1.0 and nadir view. To include the influence $\mathrm{CO}_{2}$, four sets of simulations are produced using $\mathrm{CO}_{2}$ concentrations of $330,350,370$, and $390 \mathrm{ppm}$. The influence of other greenhouse gases such as $\mathrm{NO}_{2}$ or $\mathrm{CH}_{4}$ is neglected, but it is only expected to have a minor effect (Buehler et al. 2010). We do not study the influence of sea ice or land emissivity as this study is mainly focused on tropical oceans. The presence of aerosols might also influence this regression, especially the aerosols injected into the stratosphere following the El Chichón and Mt. Pinatubo eruptions (Stenchikov et al. 1998; Pierangelo et al. 2004).

We calculate successive forward and backward multivariate regressions (von Storch and Zwiers 1999) to provide predictors of the OLR using the HIRS brightness temperatures. The stratospheric channels 1 and 2 and the ozone channel 10 were not considered as predictors. In the four sets of simulations, using the four channels at $14.2 \mu \mathrm{m}, 13.4 \mu \mathrm{m}, 11.1 \mu \mathrm{m}$, and $6.7 \mu \mathrm{m}$ (channels 4, 7, 8, and 12) provides the best predictors for estimating the clear-sky OLR, which is consistent with previous studies for all sky conditions (Ellingson et al. 1989; Lee et al. 2007). These four channels are able to reproduce $98.8 \%$ of the variance of the simulations from the soundings, with a rms error of $\pm 4.0 \mathrm{~W} \mathrm{~m}^{-2}$.

The rms error of the predicted OLR when adding channels is given in Fig. 5. We note that using five to nine channels as predictors did improve the explained 


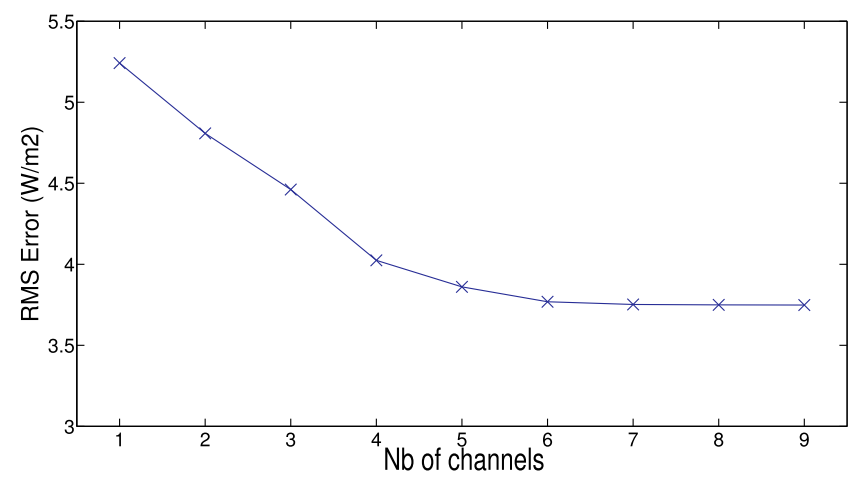

FIG. 5. Rms error for the OLR of the best multivariate regression using different total numbers of HIRS channels as predictors.

variance using the $F$ test. However, assuming a noise standard deviation of $1 \%$ for the radiance in each channel, the increased uncertainty due to possible noise is greater than the increased variance explained by this inclusion, as was found by Ellingson et al. (1989).

The OLR given the brightness temperatures $T_{b}$, referred to as OLR $\left.\right|_{T_{b}}$, is expressed as

$$
\left.\mathrm{OLR}\right|_{T_{b}}=a_{4} T_{\mathrm{b} 4}+a_{7} T_{\mathrm{b} 7}+a_{8} T_{\mathrm{b} 8}+a_{12} T_{\mathrm{b} 12}-c_{1},
$$

where $T_{\mathrm{b} 4}, T_{\mathrm{b} 7}, T_{\mathrm{b} 8}$, and $T_{\mathrm{b} 12}$ are the HIRS channel $4,7,8$, and 12 brightness temperatures in kelvin. The coefficients are $c_{1}\left(652.38 \pm 1.32 \mathrm{~W} \mathrm{~m}^{-2}\right), a_{4}(0.5951 \pm$ $\left.0.0053 \mathrm{~W} \mathrm{~m}^{-2} \mathrm{~K}^{-1}\right), a_{7}\left(1.4065 \pm 0.0163 \mathrm{~W} \mathrm{~m}^{-2} \mathrm{~K}^{-1}\right)$, $a_{8}\left(0.9765 \pm 0.0106 \mathrm{~W} \mathrm{~m}^{-2} \mathrm{~K}^{-1}\right)$, and $a_{12}(0.5093 \pm$ $\left.0.0051 \mathrm{~W} \mathrm{~m}^{-2} \mathrm{~K}^{-1}\right)$.

This formula was applied to the 20C CMIP3 model results to test the ability of the formula to reproduce the OLR trend over the historical period 1982-99, as the $20 \mathrm{C}$ simulations terminate in 2000 . The trends of the monthly clear-sky OLR calculated online by the CMIP3 models are compared with the one reconstructed from monthly HIRS brightness temperature offline simulations in Fig. 6 (blue line). The OLR deduced from HIRS reconstructions given the brightness temperatures shows a trend with a negative bias. Channel 4 is located near the center of the strong $\mathrm{CO}_{2}$ absorption band around $15 \mu \mathrm{m}$, and its rapid decrease in response to increasing $\mathrm{CO}_{2}$ causes a decrease of OLR larger than the one simulated by the models.

We corrected the OLR so that the observations reproduced the mean radiative forcing of $\mathrm{CO}_{2}$ as defined in Forster et al. (2007). We performed another set of radiative transfer simulations where the stratospheric temperatures were adjusted to a $\mathrm{CO}_{2}$ concentration of $350 \mathrm{ppm}$ for the unperturbed climate. The radiative forcing (RF) is calculated as the change of OLR over tropical profiles with stratospheric adjustment. We also

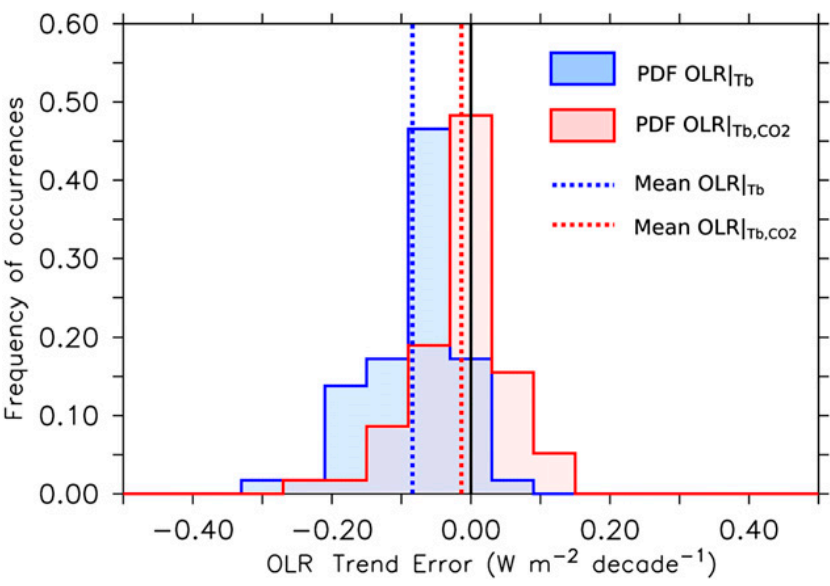

FIG. 6. Number of occurrences for the bias of clear-sky OLR trend using HIRS reconstructed OLR in the 20C runs. The bias is the difference between the reconstructed HIRS OLR without (with) $\mathrm{CO}_{2}$ term, referred to as OLR $\left.\right|_{T_{b}}\left(\left.\mathrm{OLR}\right|_{T_{b}, \mathrm{CO}_{2}}\right)$, and the model output for the blue (red) line. The trends are calculated over tropical ocean regions $\left(30^{\circ} \mathrm{N}-30^{\circ} \mathrm{S}\right)$ during $1982-99$. The multimodel-mean trend for the $20 \mathrm{C}$ simulations is given with a thick vertical line.

calculate the change of the reconstructed OLR given the brightness temperatures $\left(\left.\Delta \mathrm{OLR}\right|_{T_{b}}\right)$ when compared to the 350-ppm profiles. The $\mathrm{CO}_{2}$ term, referred to as $a_{\mathrm{CO} 2}$, is calculated as the regression of the difference $\left(\mathrm{RF}-\left.\Delta \mathrm{OLR}\right|_{T_{b}}\right.$ ) onto the $\mathrm{CO}_{2}$ concentration change $\left(\left[\mathrm{CO}_{2}\right]-350\right)$, where $\left[\mathrm{CO}_{2}\right]$ designates the atmospheric $\mathrm{CO}_{2}$ concentration in parts per million. The OLR given the brightness temperature and the $\mathrm{CO}_{2}$ concentration, $\left.\mathrm{OLR}\right|_{T_{b}, \mathrm{CO}_{2}}$, is then calculated as

$$
\left.\mathrm{OLR}\right|_{T_{b}, \mathrm{CO}_{2}}=\left.\mathrm{OLR}\right|_{T_{b}}+a_{\mathrm{CO}_{2}}\left(\left[\mathrm{CO}_{2}\right]-350\right)
$$

The value found for $a_{\mathrm{CO}_{2}}$ was $3.70 \pm 0.2910^{-3} \mathrm{~W} \mathrm{~m}^{-2} \mathrm{ppm}^{-1}$. The trend of the reconstructed OLR using Eq. (2) is closer to the simulated one in the CMIP3 20C runs (Fig. 6, red line). In the following sections, we will use Eq. (2) to reconstruct the OLR.

\section{b. Uncertainties on HIRS clear-sky OLR}

The uncertainties of the clear-sky OLR reconstructed from HIRS were assessed. The precision uncertainty originates from instrument noise, cloud clearing, and the multivariate regression. The random uncertainty due to instrument noise and cloud clearing was estimated by the intersatellite standard deviation over tropical oceanonly grid points, using all overlapping satellite periods (see Fig. 3). We found a mean intersatellite standard deviation of $\sim 2.3 \mathrm{~W} \mathrm{~m}^{-2}$. To illustrate the spatial distribution, Fig. 7 shows the map of the intersatellite standard deviation. The uncertainties are larger over the South Pacific intertropical convergence zone and the subtropical 


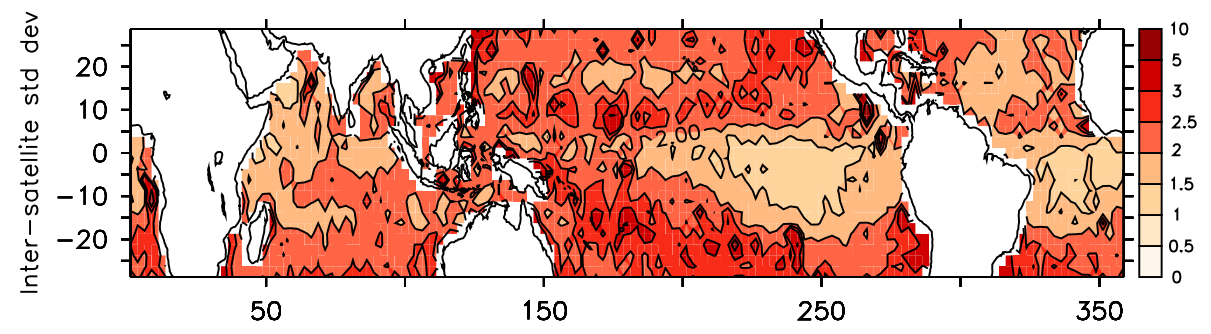

FIG. 7. Clear-sky HIRS OLR intersatellite standard deviation $\left(\mathrm{W} \mathrm{m}^{-2}\right)$.

North Pacific, while they are lower in the eastern Pacific and South Atlantic. The uncertainty owing to the multivariate regression is larger and is equal to $\sim 4.0 \mathrm{~W} \mathrm{~m}^{-2}$. The total precision uncertainty is estimated by the root of the sum of the squared uncertainties, which yielded a mean value of $\sim 4.6 \mathrm{~W} \mathrm{~m}^{-2}$ over one grid point. The systematic errors owing to cloud clearing further increase the total uncertainty, as illustrated in the comparison with ERBE and CERES in the next section, but it should not lead to stability errors.

We assume that the spatial correlation of errors between grid points was identical to the spatial correlation of the OLR anomalies between grid points. This provided an estimate of the uncertainty in the mean tropical ocean of $0.71 \mathrm{~W} \mathrm{~m}^{-2}$. Assuming that the error is independent in time for blocks of three months to account for autocorrelation, we estimate the stability uncertainty with a Monte Carlo analysis. We generated 10000 time series including a random Gaussian error with a standard deviation of $0.71 \mathrm{~W} \mathrm{~m}^{-2}$. We estimate the stability uncertainty by the standard deviation of the trend of these time series. It corresponded to a stability uncertainty of $0.20 \mathrm{~W} \mathrm{~m}^{-2}$ decade $^{-1}$ over 1982-99.

The stability uncertainty is related to orbital drift, intersatellite calibration, and multivariate regression. There is no stable record of the clear-sky OLR during the duration of the HIRS observation to assess the stability of the OLR retrievals. The stability is therefore first estimated using linear trends of the correction applied to the data. During 1982-99, the adjustments owing to orbital drift show a trend below $0.01 \mathrm{~W} \mathrm{~m}^{-2}$ decade $^{-1}$, while the $\mathrm{CO}_{2}$ term in the multivariate regression accounts for a correction in the clear-sky OLR trend of $+0.07 \mathrm{~W} \mathrm{~m}^{-2}$ decade $^{-1}$ (see Fig. 6). To estimate the stability uncertainty due to intersatellite calibration, we calculated the uncertainty of the mean climatological difference between observations of two satellites, using the total length of the overlapping period. The uncertainty of the intersatellite adjustments is calculated from the cumulated uncertainty of the difference between satellites. We generated 10000 time series with a random Gaussian error at each time step associated to the intersatellite adjustment of the observing satellite. We found that the trend of these time series has a standard deviation of $+0.32 \mathrm{~W} \mathrm{~m}^{-2}$ decade $^{-1}$, which estimates the stability uncertainty due to intersatellite calibration during 1982-99. The root of the sum of the squares of all uncertainties provides a total stability uncertainty of $\sim 0.39 \mathrm{~W} \mathrm{~m}^{-2}$ decade $^{-1}$. A similar analysis over the $1982-$ 2004 period produces a lower total stability uncertainty of $0.33 \mathrm{~W} \mathrm{~m}^{-2}$ decade $^{-1}$.

\section{c. Validation of HIRS clear-sky OLR using ERBE/CERES}

The HIRS clear-sky OLR was evaluated using the shorter records of CERES and ERBE to further assess the uncertainties of the dataset. Table 3 provides a clearsky OLR comparison among HIRS, CERES, and ERBE, while Fig. 8 shows the mean bias of HIRS clearsky OLR relative to both instruments. The clear-sky OLR reconstructed from HIRS shows a mean negative bias of $7.5 \mathrm{~W} \mathrm{~m}^{-2}\left(5.2 \mathrm{~W} \mathrm{~m}^{-2}\right)$ when compared to CERES Terra (ERBE). A large bias occurs over low cloud regions along the eastern coastlines of the major oceans. The clear-sky detection in CERES is based on the MODIS multispectral imager and is rated as $99.99 \%$ clear (Wielicki et al. 1996), while ERBE uses the longwave and shortwave irradiance (Wielicki and Green 1989) and is rated only as $95 \%$ clear. Thus, the difference in the cloud detection algorithm could account for part the mean biases difference between CERES and ERBE comparisons. The temporal sampling also accounts for the mean bias since HIRS OLR was estimated using an

TABLE 3. Mean bias and rms errors (RMSE) of HIRS clear-sky OLR $\left(\mathrm{W} \mathrm{m}^{-2}\right.$ ) average values over the ocean, between $30^{\circ} \mathrm{N}$ and $30^{\circ} \mathrm{S}$, compared with CERES and ERBE, during their overlapping period. The mean difference is positive if HIRS OLR is lower than CERES or ERBE.

\begin{tabular}{lccc}
\hline \hline & CERES & CERES & \\
& Terra & Aqua & ERBE \\
& $(2000-04)$ & $(2002-04)$ & $(1984-90)$ \\
\hline Mean difference $\left(\mathrm{W} \mathrm{m}^{-2}\right)$ & +7.5 & +8.0 & +5.2 \\
RMSE monthly means $\left(\mathrm{W} \mathrm{m}^{-2}\right)$ & 10.1 & 9.6 & 8.0 \\
RMSE deseasonalized & 4.3 & 4.3 & 3.9 \\
$\quad$ anomalies $\left(\mathrm{W} \mathrm{m}^{-2}\right)$ & & & \\
\hline
\end{tabular}




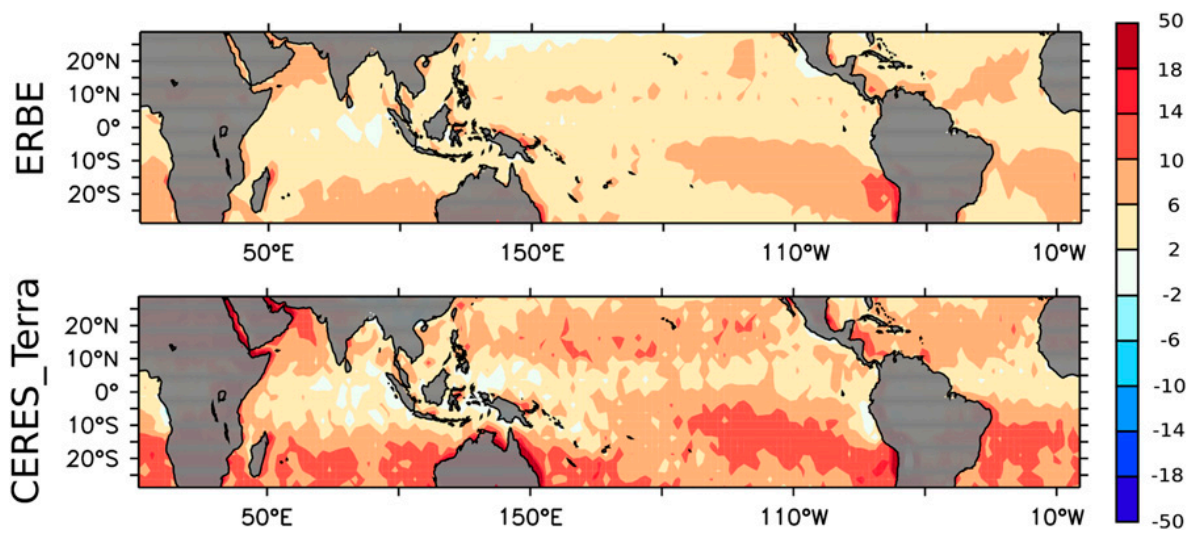

FIG. 8. (top) Mean difference (top) ERBE minus HIRS clear-sky OLR during 1984-90 and (bottom) CERES Terra minus HIRS clear-sky OLR during 2000-04, $\left(\mathrm{W} \mathrm{m}^{-2}\right)$.

average between ascending and descending orbits corresponding to late afternoon (1930 LST) and early morning (0730 LST) observations while CERES and ERBE used a regular diurnal sampling.

Figure 9 compares the rms error of the deseasonalized anomalies. The rms errors of the anomalies are $\sim 4.3 \mathrm{~W} \mathrm{~m}^{-2}\left(3.9 \mathrm{~W} \mathrm{~m}^{-2}\right)$ over the oceans for CERES (ERBE). The largest errors in HIRS clear-sky OLR are located over the northern subtropical Pacific and the South Pacific intertropical convergence zone for both CERES Terra and ERBE comparisons. These differences resemble the intersatellite standard deviation shown in Fig. 7 and are consistent with the estimate of $\sim 4.6 \mathrm{~W} \mathrm{~m}^{-2}$ for the precision uncertainty of HIRS clear-sky OLR.

The interannual variations of the clear-sky OLR averaged over tropical oceans between $30^{\circ} \mathrm{N}$ and $30^{\circ} \mathrm{S}$ (Fig. 10) demonstrate the ability of the HIRS reconstructed OLR to reproduce the CERES and to a lesser extent ERBE measurements during their common period of observation. The rms difference for the tropical ocean mean is $0.46 \mathrm{~W} \mathrm{~m}^{-2}\left(0.68 \mathrm{~W} \mathrm{~m}^{-2}\right)$ when compared to CERES Terra (ERBE). The difference compared to ERBE is larger, but it remains lower than the precision uncertainty of the HIRS clear-sky OLR $\left(0.71 \mathrm{~W} \mathrm{~m}^{-2}\right)$.

\section{OLR and greenhouse effect changes over the last decades and comparison with climate models}

\section{a. Changes of HIRS clear-sky OLR since 1982}

The changes of the monthly clear-sky OLR monitored by HIRS are shown in Fig. 11 (top). To highlight the dominant sources of interannual variability in clear-sky OLR, the observations are compared to the results from the three-member HiRAM simulations using prescribed observed SST. A reduction in OLR occurs following the Mt. Pinatubo eruption in 1991 because of two physical effects: a decrease in global temperature resulting from the volcanic aerosol-induced reduction in absorbed solar radiation and direct absorption of longwave radiation by volcanic aerosols that reduces the surface emission to space. Similarly, the warming (cooling) associated with

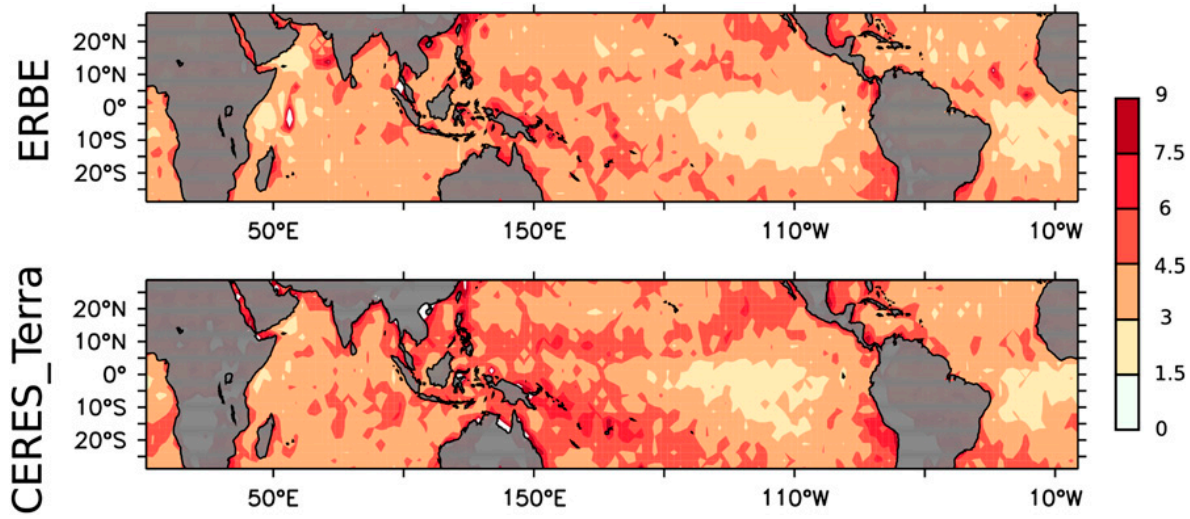

FIG. 9. Rms difference of (top) the deseasonalized anomalies of HIRS clear-sky OLR compared to ERBE during 1984-90 and (bottom) the HIRS clear-sky OLR anomalies compared to CERES Terra during 2000-04, $\left(\mathrm{W} \mathrm{m}^{-2}\right)$. 


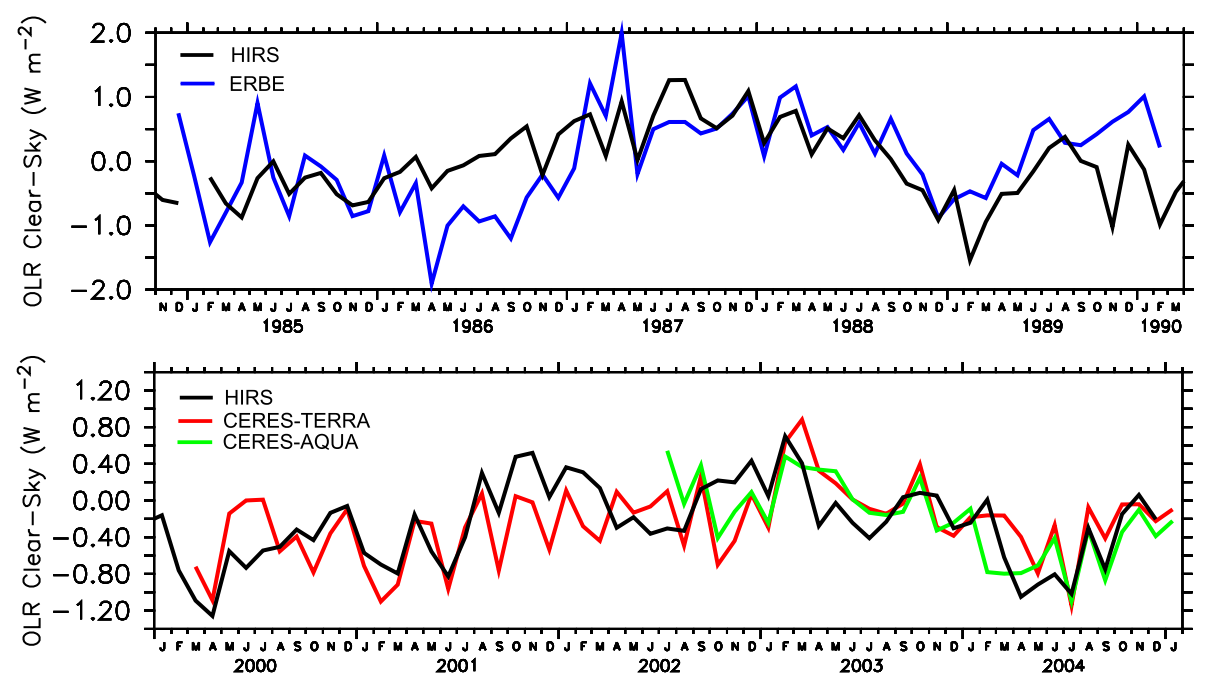

FIG. 10. Time series of clear-sky OLR $\left(\mathrm{W} \mathrm{m}^{-2}\right)$ deseasonalized anomalies, averaged over tropical oceans $\left(30^{\circ} \mathrm{N}-30^{\circ} \mathrm{S}\right)$ from HIRS and (top) ERBE and (bottom) CERES Terra and Aqua.

the El Niño (La Niña) episodes increases (decreases) the clear-sky OLR because of the resulting changes of temperature and water vapor. Both the El NiñoSouthern Oscillation (ENSO) and volcano-induced changes in OLR are the product of negative feedbacks from increasing surface emission and positive feedbacks from water vapor superimposed upon long-term increases in anthropogenic greenhouse gases (Allan 2006; Dufresne and Bony 2008; Dessler and Wong 2009; Dessler 2013). The interannual variability of the atmospheric model ensemble agrees well with the HIRS reconstructed OLR as shown by the correlation of $\mathbf{0 . 7 4}$, which underscores the central role of SST anomalies in determining both the surface emission and associated changes in atmospheric absorption by water vapor (Inamdar and Ramanathan 1998). To account for the temperature dependence of the clear-sky OLR and emphasize changes in absorption by the atmosphere, we define the atmospheric greenhouse effect (Raval and Ramanathan 1989), as

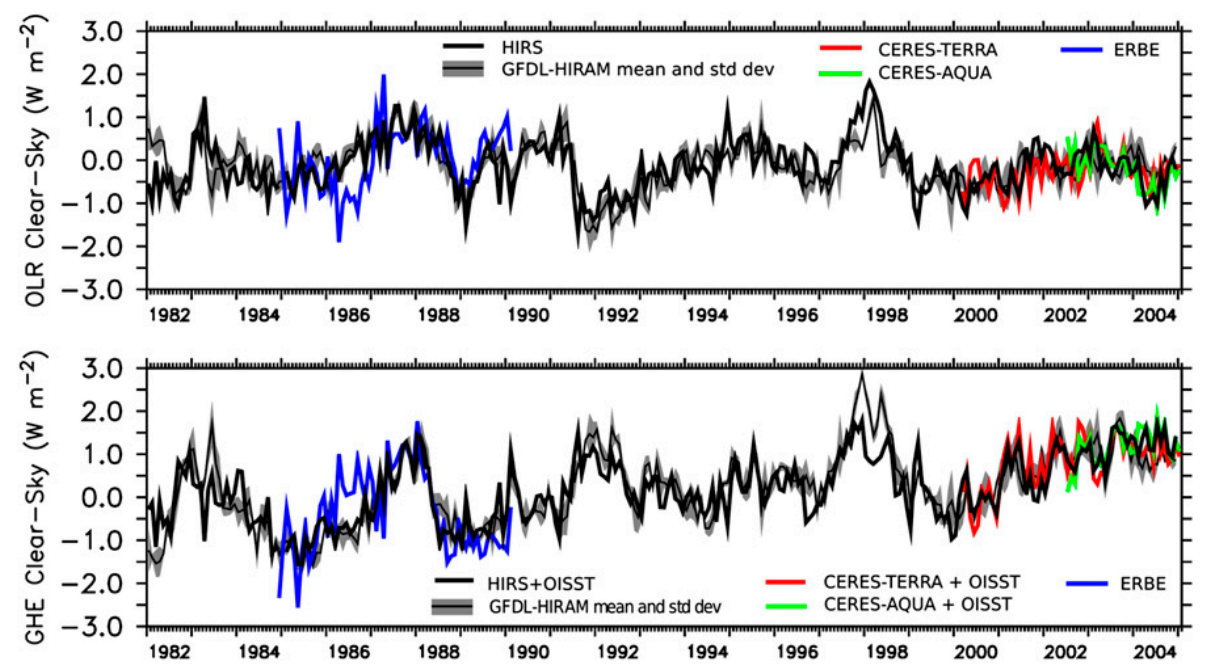

FIG. 11. Time series of clear-sky OLR and greenhouse effect $\left(\mathrm{W} \mathrm{m}^{-2}\right)$ deseasonalized anomalies, averaged over tropical oceans $\left(30^{\circ} \mathrm{N}-30^{\circ} \mathrm{S}\right)$. The HIRS clear-sky OLR is compared with ERBE and CERES TerralAqua. The thin black line indicates the clear-sky OLR from ensemble mean of HiRAM simulations, while gray shades indicate the standard deviation among the ensemble members. The mean anomaly for ERBE and CERES Terral Aqua and HiRAM are shifted with the mean anomaly of HIRS OLR for each particular period. 
TABLE 4. Trend of HIRS clear-sky OLR and GHE averaged over ocean between $30^{\circ} \mathrm{N}$ and $30^{\circ} \mathrm{S}$, and $95 \%$ statistical confidence intervals using the autocorrelation to reduce the degrees of freedom (Bretherton et al. 1999). The trend of OI-SST is also shown. The trends are shown in italics if they are statistically significant at the $5 \%$ level.

\begin{tabular}{|c|c|c|}
\hline & $\begin{array}{c}\text { Period } \\
\text { 1982-2004 }\end{array}$ & $\begin{array}{c}\text { Period } \\
\text { 1982-99 }\end{array}$ \\
\hline Clear-sky OLR $\left(\mathrm{W} \mathrm{m}^{-2}\right.$ decade $\left.^{-1}\right)$ & $-0.09 \pm 0.12$ & $0.15 \pm 0.12$ \\
\hline Clear-sky GHE (W m ${ }^{-2}$ decade $\left.^{-1}\right)$ & $0.80 \pm 0.13$ & $0.75 \pm 0.21$ \\
\hline SST $\left(\mathrm{K}_{\text {decade }}^{-1}\right)$ & $0.12 \pm 0.04$ & $0.16 \pm 0.05$ \\
\hline
\end{tabular}

$$
\mathrm{GHE} \equiv \varepsilon \sigma T^{4}-\mathrm{OLR},
$$

where $\sigma$ is the Stefan-Boltzmann constant, $T$ the sea surface temperature, and $\varepsilon$ the surface emissivity—assumed to be unity for oceans. The GHE parameter measures the difference in the upwelling longwave radiation between the surface and the TOA and increases as the longwave absorption from greenhouse gases increases. Different definitions of the greenhouse parameter are possible but generally result in similar behavior in practice (Webb et al. 1993). The reconstructed HIRS OLR is combined with SST observations to compute the GHE over sea surfaces. As shown previously by (Slingo et al. 1998), the interannual anomalies in GHE are strongly correlated with changes in surface temperature through changes in atmospheric water vapor (Fig. 11, bottom). The GHE increases during El Niño episodes (e.g., 1982-83 or 199798 ) when the atmosphere warms and moistens, and decreases during La Niña (e.g., 1985, 1999) when the atmosphere cools and dries.

The trends and their uncertainty at the $95 \%$ confidence limit are estimated for the 1982-2004 period when SST and OLR estimations are available (see Table 4). The OLR trend is not significant, $-0.09 \pm$ $0.12 \mathrm{~W} \mathrm{~m}^{-2}$ decade $^{-1}$, while the observed GHE shows a large significant increase of $0.80 \pm 0.13 \mathrm{~W} \mathrm{~m}^{-2} \mathrm{decade}^{-1}$ that is larger than the stability uncertainty of HIRS. In comparison, the SST increased by $0.12 \pm 0.04 \mathrm{~K} \mathrm{decade}^{-1}$ (significant), which represents a global increase of $\sim 0.2 \mathrm{~K}$ (Reynolds et al. 2002).

To assess the contribution of anthropogenic forcing to the observed trend in the GHE, Fig. 12 compares the observations to multimodel ensemble-mean simulations from the CMIP 3 under both preindustrial control (CTRL) conditions in which radiative forcings are fixed and simulations in which the observed twentiethcentury (20C) and projected twenty-first-century (A1B) radiative forcings are prescribed. Because the impact of volcanic aerosols is not included in all $20 \mathrm{C}$ simulations, the multimodel ensemble means are computed separately for models including forcing from volcanic aerosols.
Both HIRS-observed and the model-simulated OLR anomalies are nearly stable over 1982-2004, the period of record (Fig. 12, top). The absence of a trend in OLR reflects the competing effects of surface (and atmospheric) warming, which increases the emission of OLR and increasing greenhouse gas concentrations, which decreases the OLR. An absence of trend in the clear-sky OLR in the presence of a warming climate requires an increase in greenhouse gas concentrations. Since the clear-sky GHE accounts for changes in longwave emission from both the surface and TOA, it provides a more robust metric for detecting anthropogenic changes (Fig. 12, bottom). Both observations and radiatively forced model simulations exhibit a distinct increase in the GHE over this period, while the CTRL simulations show no significant trend.

Because of their large impact on global temperature, only the models with volcanoes are in agreement with HIRS for the years following the Mt. Pinatubo eruption, during 1991-93. The consequences of the El Chichón eruption (1982) are weaker but also evident in the OLR of the models. However, the effect of El Chichón is masked out in observations by the 1982-83 El Niño event while climate variability in the multimodel ensemble mean is muted.

\section{b. Attribution of HIRS clear-sky OLR changes}

To evaluate the likelihood of obtaining the observed trend in GHE owing to natural or anthropogenic forcings, we compare the linear trends of the OLR (Fig. 13), GHE, and SST (Fig. 14) over tropical oceans in observations (vertical black line) with the model simulations (colored bars). Since the observational data begin in 1982 while the CMIP3 20C simulations terminate in 2000, we used the period 1982-99 to compare models and observations. The frequency of 1982-99 trend occurrences for the individual simulations is computed from all $20 \mathrm{C}$ ensemble members of the 21 models, each model using the same weight (green bars in Fig. 13, left). We also add the uncertainty for the observed HIRS trend (gray shading) that resulted from the statistical analysis (the $95 \%$ confidence interval shown in dark gray) and the stability uncertainty (shown in light gray). For the OLR, the observed trend is weakly positive over $1982-2000\left(+0.15 \mathrm{~W} \mathrm{~m}^{-2}\right.$ decade $\left.^{-1}\right)$ and lies at the tail of the distribution of the $20 \mathrm{C}$ simulations trends. However, 44 ensemble members out of $66(67 \%)$ show a clearsky OLR trend within the stability uncertainty of HIRS observations. Note that the observed trend calculated over 1982-2004 $\left(-0.09 \mathrm{~W} \mathrm{~m}^{-2}\right.$ decade $\left.^{-1}\right)$ is more similar to the results of models, so the trend value depends on the period considered but remains insignificant. The clearsky OLR trend calculated over both land and ocean 

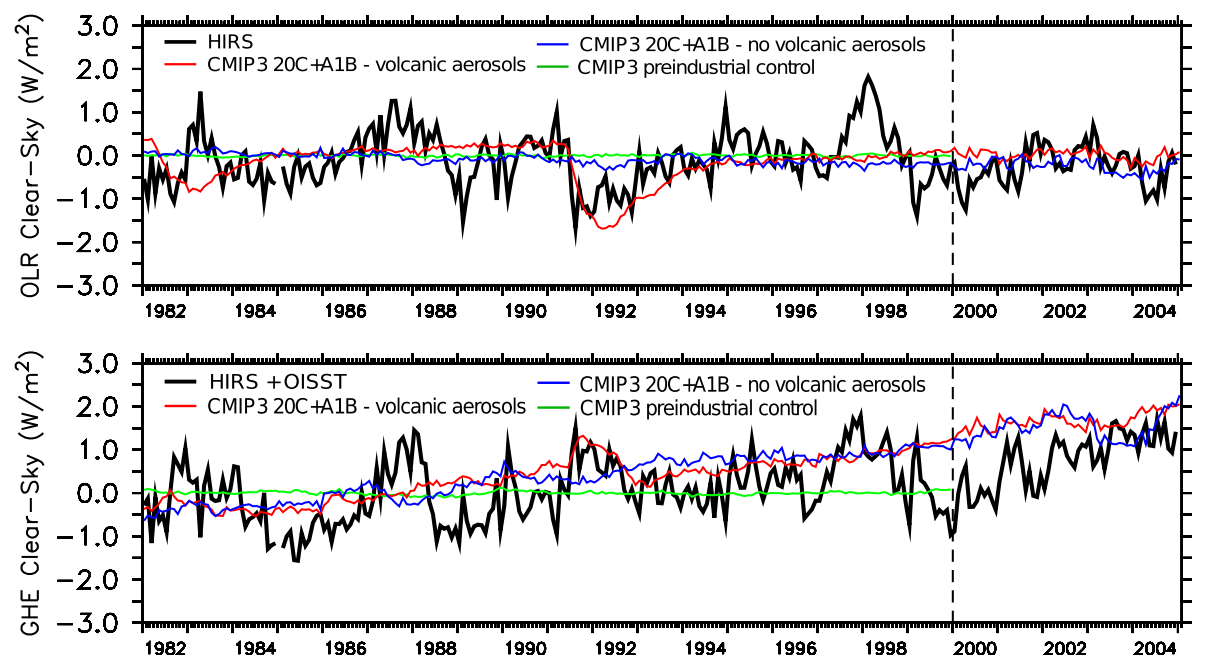

FIG. 12. Time series of clear-sky OLR and GHE $\left(\mathrm{W} \mathrm{m}^{-2}\right)$ deseasonalized anomalies, averaged between $30^{\circ} \mathrm{N}$ and $30^{\circ} \mathrm{S}$ over sea surfaces, from HIRS and from the multimodel mean of the coupled models. The results are from the merged 20C/A1B and CTRL simulations. The dashed vertical line indicates the separation between the $20 \mathrm{C}$ and $\mathrm{A} 1 \mathrm{~B}$ simulations periods.

between $30^{\circ} \mathrm{N}$ and $30^{\circ} \mathrm{S}$ in models (Fig. 13, left, black dashed line) is not different from the OLR trend over ocean only. Therefore, the ocean-only grid points are well representative of the clear-sky changes occurring in the tropics.

The CMIP3 multimodel mean (blue line in Fig. 13) shows a decrease of the OLR driven by the greenhouse gases increase as found in Trenberth and Fasullo (2009), but the observed OLR is found to be stable during 19822004 and shows a weak increase during 1982-99. The natural climate variability such as ENSO, the interdecadal Pacific variability, the Atlantic multidecadal variability, and aerosol effects play a major role in reality. The natural climate variability is muted in the multimodel mean, while the aerosol direct effect is misrepresented in the CMIP3 simulations (Wild and Schmucki 2011), so that results from CMIP3 models are not analogous to the observed clear-sky OLR trend.

The observed trend in GHE is relatively weak compared with most 20C simulation trends (Fig. 14, top left), which is likely because of natural climate variability, especially ENSO. We found that 32 simulations of the $20 \mathrm{C}$ ensemble out of $66(48 \%)$ show a trend within the total uncertainty of the observed GHE. Figure 14 (bottom left) shows a similar analysis for the SST trend. In contrast to the OLR, the modeled SST agrees well with the observed one. The SST increases at the rate of $0.13 \mathrm{~K} \mathrm{decade}^{-1}$ in models, while the observed value of $0.16 \mathrm{~K} \mathrm{decade}^{-1}$ is only slightly larger. The spread of the GHE trend of the $20 \mathrm{C}$ models is large, which reflects the spread of the SST trend among models, but the difference in water vapor and lapse rate feedback might also contribute. Note that the inclusion of land grid points leads to a slightly larger GHE trend in models, as the surface warming is larger over land in model simulations (Fig. 14, top left, black dashed line).

To determine if the natural climate variability could explain the observed trend, we used the CTRL simulations and computed the linear trends from 552 nonoverlapping 18-yr segments to sample the unforced natural climate variability (Fig. 13, right; see Table 2 for model details). The observed clear-sky OLR trend is not significantly different from the simulated one in the CTRL simulations. On the other hand, only $0.5 \%$ of the segments (3 out of 552) have an 18-yr trend within or above the uncertainty of the observed GHE trend (Fig. 14, top right) owing to stability and precision. Therefore, we conclude that the observed trend in GHE is inconsistent with natural climate variability, which is consistent with a climate response to anthropogenic forcing over this period. A similar analysis using the SST trend over tropical oceans reveals that the SST trend in CTRL simulations is also significantly lower than the observed one (Fig. 14, bottom right).

\section{c. Clear-sky OLR response to SST}

Comparing the coupled model simulation and observations for a particular time period is difficult as the internal climate variability may dominate the long-term changes over two or three decades. Such variability is expected to be different in model simulations and observations. To allow for a direct comparison between 

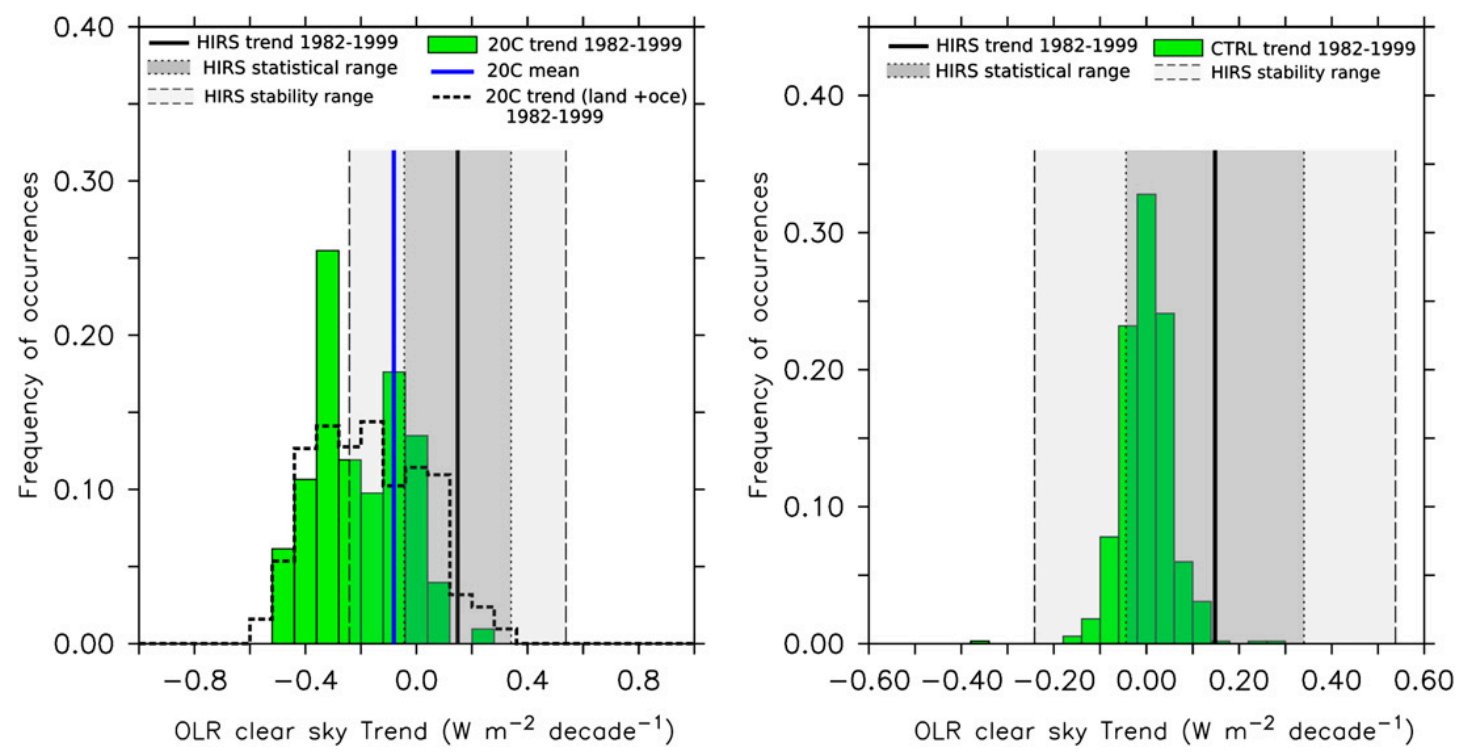

FIG. 13. Frequency of occurrences for the clear-sky OLR trend during 1982-99 in the (left) 20C and (right) CTRL simulations, over tropical oceans (green bars) and for both tropical land and ocean (black dashed line). The trend of the HIRS observations from 1982 to 1999 (vertical black line), the 95\% confidence interval (dark gray shade), the stability uncertainty (light gray shades), and the multimodel-mean trend for the 20C simulations (vertical blue line) are shown.

model and observation, we calculate the rate of change of clear-sky OLR for an increase of $1 \mathrm{~K}$ of tropical SST using a least squares regression of the mean clear-sky OLR onto the mean SST, over tropical oceans. Dessler (2013) indicated that this diagnostic shows the dominant climate variation from ENSO and is not strictly equivalent to the global warming response. However, it can be used to assess the feedback processes in models.

Figure 15 shows the clear-sky OLR sensitivity to SST in models with the probability density function of the 20C and CTRL ensemble members. The thick black line indicates the OLR response to SST for observations, while the dark gray shade shows the statistical uncertainty, that is, the $95 \%$ confidence interval. Note that a period of $18 \mathrm{yr}$ is used both in observation and models so that the regression is estimated using records of the same length. We found a value of $2.1 \pm 0.4 \mathrm{~W} \mathrm{~m}^{-2} \mathrm{~K}^{-1}$ for the OLR sensitivity to SST in observations. Assuming that the error is independent over a 3-month time period, we find using a Monte Carlo analysis that the precision uncertainty corresponds to an error with a standard deviation of $0.49 \mathrm{~W} \mathrm{~m}^{-2} \mathrm{~K}^{-1}$ (light gray shade in Fig. 15).

The OLR response to SST is a measure of the water vapor plus temperature feedback over tropical oceans as a response to ENSO variability. The observational value lies in the center of the model distribution, which demonstrates the ability of global climate models to simulate the climate response to ENSO. The CTRL and $20 \mathrm{C}$ ensemble provide a similar OLR sensitivity to SST and are within the statistical and stability uncertainty of observations. However, the multimodel mean of the $20 \mathrm{C}$ and CTRL ensemble are slightly lower than that of observations, as some model simulations systematically underestimate the OLR response to SST, which may be linked to misrepresentation of the ENSO phenomenon in some models, as found by Dessler (2013).

As the OLR response to SST is similar in models and observation, the sum of water vapor and temperature feedbacks in response to ENSO is well simulated in models. It suggests that the water vapor and temperature feedbacks are not the cause of the trend difference between 20C simulation and observations. Instead, the observed trend may be largely influenced by natural climate variability. A misrepresentation of the external forcing such as the one of aerosols may also explain these differences.

\section{Discussion and conclusions}

We show that a multivariable regression can be used to retrieve a clear-sky OLR from HIRS that compares favorably with other state-of-the-art OLR measurements from CERES or ERBE. Even though the precision uncertainty is $4.7 \mathrm{~W} \mathrm{~m}^{-2}$, the HIRS clear-sky OLR can be used to assess the large-scale changes over the tropical oceans. The stability uncertainty is mostly due to intersatellite calibration and is found to be of the order of $\sim 0.39 \mathrm{~W} \mathrm{~m}^{-2}$ decade $^{-1}$. 

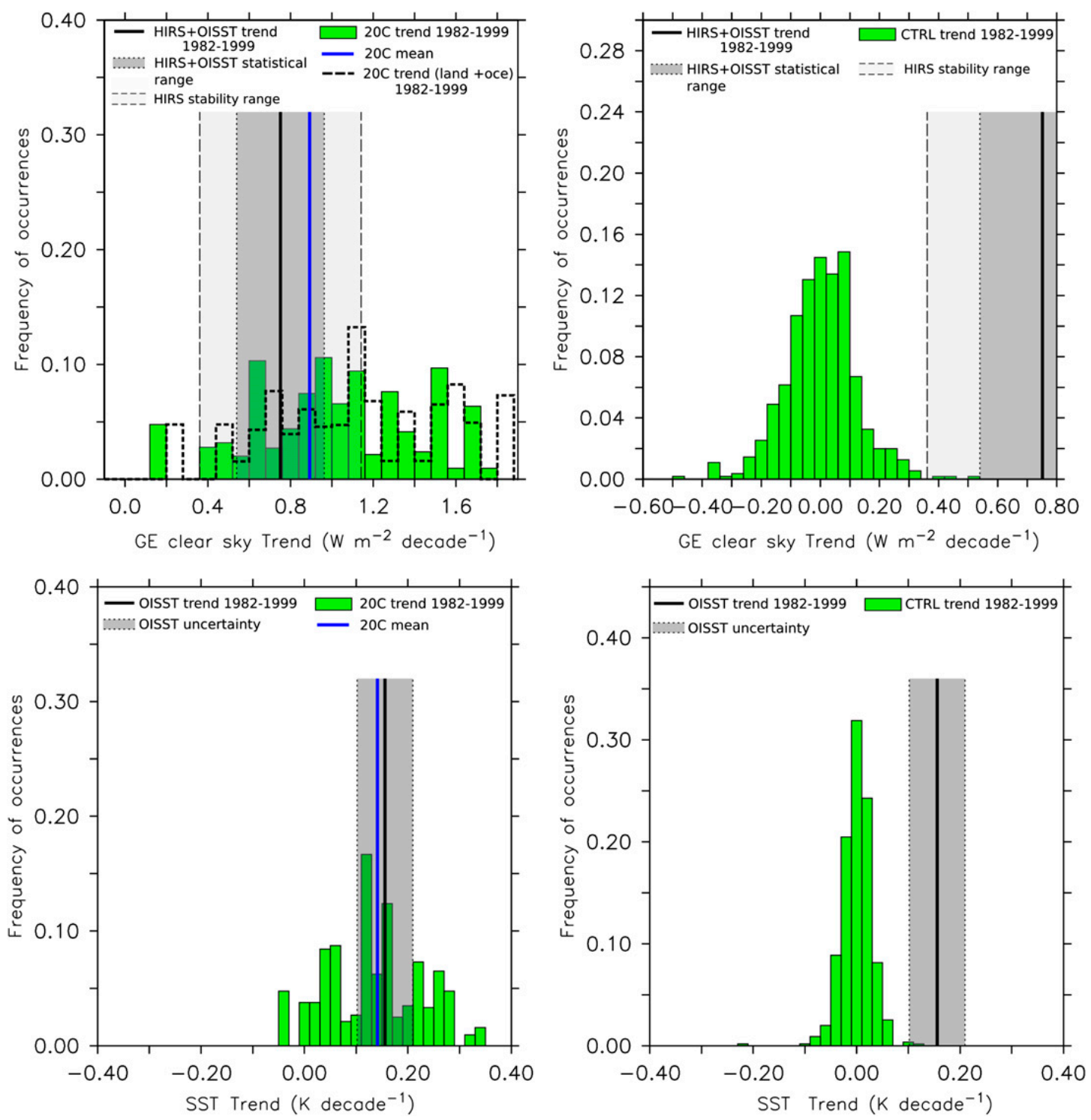

FIG. 14. As in Fig. 13, but for the trend of (top) clear-sky GHE and (bottom) SST.

Our findings demonstrate that the clear-sky OLR over tropical oceans was slightly decreasing over the last two decades $\left(-0.09 \pm 0.12 \mathrm{~W} \mathrm{~m}^{-2}\right.$ decade $\left.^{-1}\right)$ while the climate warmed. The decrease in the clear-sky OLR is not significant as it is within than the estimated stability of HIRS OLR. Conversely, the difference between the surface and TOA emission of longwave radiation, that is, the greenhouse effect, increased significantly at the rate of $+0.80 \pm 0.13 \mathrm{~W} \mathrm{~m}^{-2}$ decade $^{-1}$ over the satellite observation period (1982-2004). We showed that the GHE increase is inconsistent with natural variability and only reproduced if simulations include anthropogenic forcing. Even if HIRS observations are restricted to tropical ocean surfaces in this study, similar trends in clear-sky OLR and GHE are found in models when including the tropical land grid points in model simulation results. The nearly stable OLR found in the presence of SST warming confirms that greenhouse gases are the cause of the warming during 1982-2004.

The surface and tropospheric warming occurred with nearly constant OLR during 1982-2004, while the outgoing longwave radiation shows a weak increase in 1982-99. Conversely, most model simulations show a decrease of the OLR as a response to increased greenhouse gas concentration (Trenberth and Fasullo 2009). It results in an observed greenhouse effect weaker than the one of climate model simulations, even if the majority of climate models are within the stability uncertainty of HIRS clear-sky OLR. We found that the OLR response to SST over the tropical oceans is similar in models and observations, so climate models simulate well the water vapor and temperature feedbacks during 


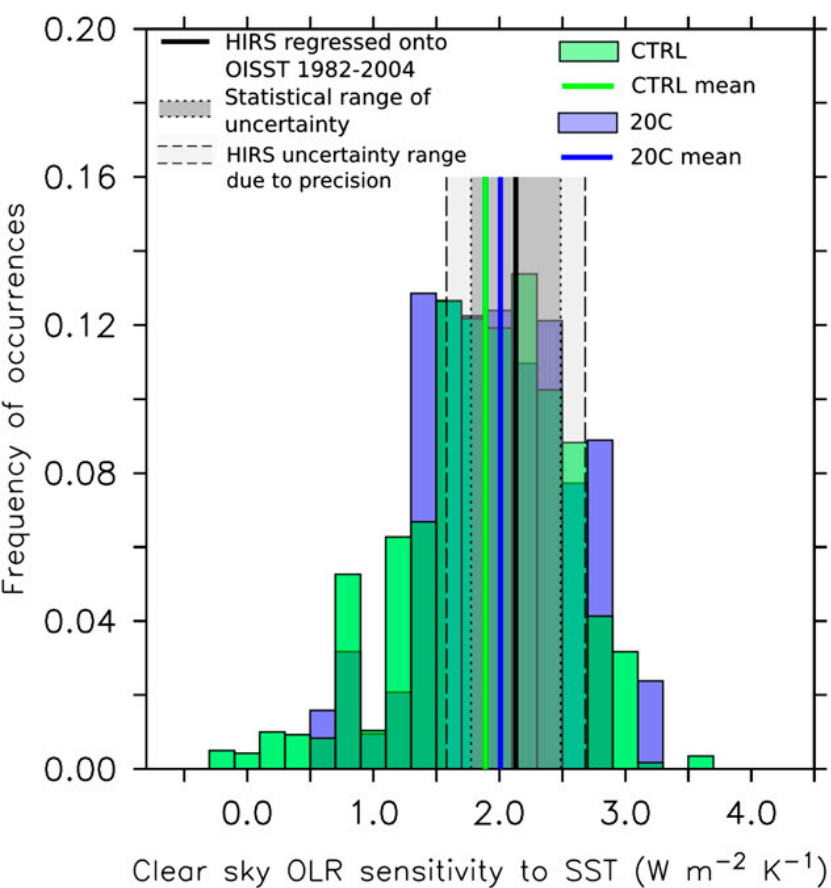

FIG. 15. Frequency of occurrence for the clear-sky OLR sensitivity to SST in the 20C (blue bars) and CTRL (green bars) simulations, over tropical oceans. The sensitivity of the HIRS clear-sky OLR to SST during 1982-2004 (vertical black line), the 95\% confidence interval (dark gray shade), the uncertainty due to precision (light gray shades), and the multimodel-mean trend for the $20 \mathrm{C}$ (vertical blue line) and CTRL (vertical green line) simulations are shown.

ENSO. This suggests that the ocean-atmosphere heat exchanges played a role in the observed warming. The mean tropical SST and OLR can vary over several decades without any influence from greenhouse gases owing to internal climate variability from ENSO, interdecadal Pacific variability, or Atlantic Multidecadal variability. Such internal variability can lead to the temporary accelerated warming or hiatus during several decades on top of the mean warming trend (Meehl et al. 2013; Balmaseda et al. 2013). The influence of aerosols may also be different in models and in reality, and the rapid warming of the 1990s was shown to be strongly linked to decreasing aerosol optical depth and increasing shortwave radiation reaching the earth's surface, a phenomenon known as global brightening (Wild 2012).

This study demonstrates the ability of HIRS to reconstruct clear-sky climate processes. The HIRS clearsky OLR observation could be extended by including the HIRS/3 measurements. Other methods of intercalibration could also be tested to better document and correct the large stability uncertainty of the data, using for instance the spectral response functions for each instrument, as in Chen et al. (2013). The clear-sky OLR HIRS data presented here could also be used in a wide range of studies to assess cloud processes or climate feedbacks. We found an insignificant decrease of the clear-sky OLR of $-0.09 \mathrm{~W} \mathrm{~m}^{-2}$ decade $^{-1}$ between 1982 and 2004 while the all-sky tropical OLR was reported to have increased by a value of $\sim 0.7 \mathrm{~W} \mathrm{~m}^{-2}$ decade $^{-1}$ from 1982 to 2004 (Andronova et al. 2009). This result is consistent with a decrease of the upper cloud cover; however, more work is needed to confirm this finding and understand the cloud processes behind it.

Acknowledgments. The CERES and ERBE data were obtained from the NASA Langley Research Center EOSDIS Distributed Active Archive Center. We acknowledge the modeling groups, the Program for Climate Model Diagnosis and Intercomparison (PCMDI) and the WCRP Working Group on Coupled Modeling (WGCM) for their roles in making available the WCRP CMIP3 and CMIP5 multimodel dataset. Support of this dataset is provided by the Office of Science, U.S. Department of Energy. We thank G. Stephens, V. Ramaswamy, and D. Schwarzkopf for their comments and suggestions. We thank N. Worm for providing us the outputs of BUGRADS radiative transfer simulations.

\section{REFERENCES}

Allan, R., 2006: Variability in clear-sky longwave radiative cooling of the atmosphere. J. Geophys. Res., 111, D22105, doi:10.1029/ 2006JD007304.

Andronova, N., J. Penner, and T. Wong, 2009: Observed and modeled evolution of the tropical mean radiation budget at the top of the atmosphere since 1985. J. Geophys. Res., 114, D14106, doi:10.1029/2008JD011560.

Balmaseda, M. A., K. E. Trenberth, and E. Källén, 2013: Distinctive climate signals in reanalysis of global ocean heat content. Geophys. Res. Lett., 40, 1754-1759, doi:10.1002/grl.50382.

Barkstrom, B. R., 1984: The Earth Radiation Budget Experiment (ERBE). Bull. Amer. Meteor. Soc., 65, 1170-1185.

Bony, S., and Coauthors, 2006: How well do we understand and evaluate climate change feedback processes? J. Climate, 19, 3445-3482.

Bretherton, C., M. Widmann, V. Dymnikov, J. Wallace, and I. Bladé, 1999: The effective number of spatial degrees of freedom of a time-varying field. J. Climate, 12, 1990-2009.

Buehler, S. A., V. O. John, A. Kottayil, M. Milz, and P. Eriksson, 2010: Efficient radiative transfer simulations for a broadband infrared radiometer combining a weighted mean of representative frequencies approach with frequency selection by simulated annealing. J. Quant. Spectrosc. Radiat. Transfer, 111, 602-615, doi:10.1016/j.jqsrt.2009.10.018.

Cao, C., H. Xu, J. Sullivan, L. McMillin, P. Ciren, and Y.-T. Hou, 2005: Intersatellite radiance biases for the High-Resolution Infrared Radiation Sounders (HIRS) on board NOAA-15, -16, and -17 from simultaneous nadir observations. J. Atmos. Oceanic Technol., 22, 381-395.

Chen, R., C. Cao, and P. Menzel, 2013: Intersatellite calibration of NOAA HIRS $\mathrm{CO}_{2}$ channels for climate studies. J. Geophys. Res. Atmos., 118, 5190-5203, doi:10.1002/jgrd.50447. 
Chevallier, F., A. Chédin, F. Cheruy, and J.-J. Morcrette, 2000: TIGR-like atmospheric-profile databases for accurate radiative-flux computation. Quart. J. Roy. Meteor. Soc., 126, 777-785.

Dessler, A. E., 2013: Observations of climate feedbacks over 200010 and comparisons to climate models. J. Climate, 26, 333-342. and S. Wong, 2009: Estimates of the water vapor climate feedback during El Niño-Southern Oscillation. J. Climate, 22, 6404-6412.

Douglass, D. H., and R. S. Knox, 2005: Climate forcing by the volcanic eruption of Mount Pinatubo. Geophys. Res. Lett., 32, L05710, doi:10.1029/2004GL022119.

Dufresne, J.-L., and S. Bony, 2008: An assessment of the primary sources of spread of global warming estimates from coupled atmosphere-ocean models. J. Climate, 21, 5135-5144.

Ellingson, R., D. Yanuk, H.-T. Lee, and A. Gruber, 1989: A technique for estimating outgoing longwave radiation from HIRS radiance observations. J. Atmos. Oceanic Technol., 6, 706-711.

Forster, P., and Coauthors, 2007: Changes in atmospheric constituents and in radiative forcing. Climate Change 2007: The Physical Science Basis, S. Solomon et al., Eds., Cambridge University Press, 129-234.

Iacono, M., E. Mlawer, S. Clough, and J.-J. Morcrette, 2000: Impact of an improved longwave radiation model, RRTM, on the energy budget and thermodynamic properties of the NCAR community climate model, CCM3. J. Geophys. Res., 105 (D11), 14873-14890.

Inamdar, A., and V. Ramanathan, 1998: Tropical and global scale interactions among water vapor, atmospheric greenhouse effect, and surface temperature. J. Geophys. Res., 103 (D24), 32177-32194.

Jackson, D., and J. J. Bates, 2000: A 20-yr TOVS radiance pathfinder data set for climate analysis. Preprints, 10th Conf. on Satellite Meteorology and Oceanography, Long Beach, CA, Amer. Meteor. Soc., JP4.11.

— , and B. Soden, 2007: Detection and correction of diurnal sampling bias in HIRS/2 brightness temperatures. J. Atmos. Oceanic Technol., 24, 1425-1438.

Kidwell, K. B., 1998: NOAA Polar Orbiter data users guide (TIROS-N, NOAA-6, NOAA-7, NOAA-8, NOAA-9, NOAA-10, NOAA-11, NOAA-12, NOAA-13 and NOAA14). NOAA/NESDIS/NCDC Rep., 20 pp.

Lee, H.-T., A. Gruber, R. Ellingson, and I. Laszlo, 2007: Development of the HIRS outgoing longwave radiation climate dataset. J. Atmos. Oceanic Technol., 24, 2029-2047.

Meehl, G. A., A. Hu, J. Arblaster, J. Fasullo, and K. E. Trenberth, 2013: Externally forced and internally generated decadal climate variability associated with the interdecadal Pacific oscillation. J. Climate, 26, 7298-7310.

Meinshausen, M., and Coauthors, 2011: The RCP greenhouse gas concentrations and their extensions from 1765 to 2300 . Climatic Change, 109, 213-241.
Pierangelo, C., A. Chédin, and P. Chazette, 2004: Measurements of stratospheric volcanic aerosol optical depth from NOAA TIROS Observational Vertical Sounder (TOVS) observations. J. Geophys. Res., 109, D03207, doi:10.1029/2003JD003870.

Ramanathan, V., 1981: The role of ocean-atmosphere interactions in the $\mathrm{CO}_{2}$ climate problem. J. Atmos. Sci., 38, 918-930.

Raval, A., and V. Ramanathan, 1989: Observational determination of the greenhouse effect. Nature, 342, 758-761.

Reynolds, R., N. Rayner, T. Smith, D. Stokes, and W. Wang, 2002: An improved in situ and satellite SST analysis for climate. J. Climate, 15, 1609-1625.

Saunders, R., M. Matricardi, and P. Brunel, 1999: An improved fast radiative transfer model for assimilation of satellite radiance observations. Quart. J. Roy. Meteor. Soc., 125, 1407-1425.

Slingo, A., J. Pamment, and M. Webb, 1998: A 15-year simulation of the clear-sky greenhouse effect using the ECMWF reanalyses: Fluxes and comparisons with ERBE. J. Climate, 11, 690-708.

Smith, W. L., H. M. Woolf, C. M. Hayden, and A. J. Schreiner, 1985: The simultaneous export retrieval package. Proc. Second Int. TOVS Study Conf., Igls, Austria, TOVS, 244-253.

Stenchikov, G. L., I. Kirchner, A. Robock, H.-F. Graf, J. Antuna, R. G. Grainger, A. Lambert, and L. W. Thomason, 1998: Radiative forcing from the 1991 Mount Pinatubo volcanic eruption. J. Geophys. Res., 103 (D12), 13 837-13857.

Trenberth, K. E., and J. T. Fasullo, 2009: Global warming due to increasing absorbed solar radiation. Geophys. Res. Lett., 36, L07706, doi:10.1029/2009GL037527.

von Storch, H., and F. W. Zwiers, 1999: Statistical Analysis in Climate Research. Cambridge University Press, 484 pp.

Webb, M. J., A. Slingo, and G. L. Stephens, 1993: Seasonal variations of the clear-sky greenhouse effect: The role of changes in atmospheric temperatures and humidities. Climate Dyn., 9, 117-129.

Wielicki, B. A., and R. N. Green, 1989: Cloud identification for ERBE Radiative flux retrieval. J. Appl. Meteor., 28, 11331146.

- and Coauthors, 1996: Clouds and the Earth's Radiant Energy System (CERES): An Earth Observing System experiment. Bull. Amer. Meteor. Soc., 77, 853-868.

Wild, M., 2012: Enlightening global dimming and brightening. Bull. Amer. Meteor. Soc., 93, 27-37.

- and E. Schmucki, 2011: Assessment of global dimming and brightening in IPCC-AR4/CMIP3 models and ERA40. Climate Dyn., 37, 1671-1688.

Wylie, D., D. L. Jackson, W. P. Menzel, and J. J. Bates, 2005: Trends in global cloud cover in two decades of HIRS observations. J. Climate, 18, 3021-3031.

Zhao, M., I. M. Held, S.-J. Lin, and G. A. Vecchi, 2009: Simulations of global hurricane climatology, interannual variability, and response to global warming using a 50-km-resolution GCM. J. Climate, 22, 6653-6678. 